\title{
LITERASI DAN EFIKASI KEUANGAN TERHADAP MINAT MAHASISWA BERINVESTASI DI PASAR MODAL
}

\author{
Tri Pangestika \\ tripangestika@gmail.com \\ Ellen Rusliati \\ Fakultas Ekonomi dan Bisnis, Universitas Pasundan \\ diterima: 8/3/2018; direvisi: 12/9/2018; diterbitkan: 27/2/2019
}

\begin{abstract}
This study aims to determine how the literacy and financial efficacy of interest in investing in the capital market. Data collection and library techniques are already done by giving questionnaires to 83 students of the Faculty of Economics and Business in Pasundan University that has been determined criteria in order to get a representative result. Methods of data analysis are multiple regression, multiple analysis, coefficient of determination analysis and hypothesis testing. The results showed that the financial, financial and student literacy in the Faculty of Economics and Business of Pasundan University was categorized as good. Simultaneously literacy and financial efficacy have a significant influence that is $85.3 \%$ of interest in investment, partially financial literacy has a significant influence that is equal to $79.9 \%$ of student investment interest and financial efficacy has a significant influence of 5.4 to interest in student investment.
\end{abstract}

Keywords: financial literacy; financial efficacy; college student's investment interest

\begin{abstract}
Abstrak
Penelitian ini bertujuan untuk mengetahui pengaruh literasi dan efikasi keuangan terhadap minat berinvestasi di pasar modal. Data dikumpulkan melalui kuesioner kepada 83 mahasiswa Fakultas Ekonomi dan Bisnis Universitas Pasundan yang telah ditentukan kriterianya agar mendapatkan hasil yang representatif. Metode analisis data yang digunakan adalah analisis regresi linier berganda, analisis korelasi berganda, analisis koefisien determinasi. Hasil penelitian menunjukkan bahwa literasi keuangan, efikasi keuangan dan minat investasi mahasiswa berada pada kategori baik. Secara simultan literasi dan efikasi keuangan memiliki pengaruh siginifikan sebesar $85,3 \%$ terhadap minat investasi mahasiswa, secara parsial literasi keuangan memiliki pengaruh signifikan sebesar $79,9 \%$ terhadap minat investasi mahasiswa dan efikasi keuangan memiliki pengaruh signifikan sebesar 5,4\%.
\end{abstract}

Kata Kunci: literasi keuangan; efikasi keuangan; minat investasi mahasiswa 


\section{PENDAHULUAN}

Investasi pada pasar keuangan menjadi cara yang mulai digemari investor. Saat ini terdapat banyak instrumen keuangan, seperti yang ada pada pasar uang yaitu deposito dan tabungan termasuk kas yang nilainya ditentukan langsung oleh pasar, lalu ada saham dan obligasi di pasar modal. Gambar 1 menunjukkan bahwa keuntungan instrumen keuangan pasar modal paling tinggi, akan tetapi juga memiliki risiko paling tinggi. Investasi di pasar modal biasanya dilakukan untuk jangka panjang, sehingga menimbulkan berbagai risiko seperti harga saham atau obligasi yang naik dan turun dengan tidak terkendali dan perubahan kondisi perusahaan.

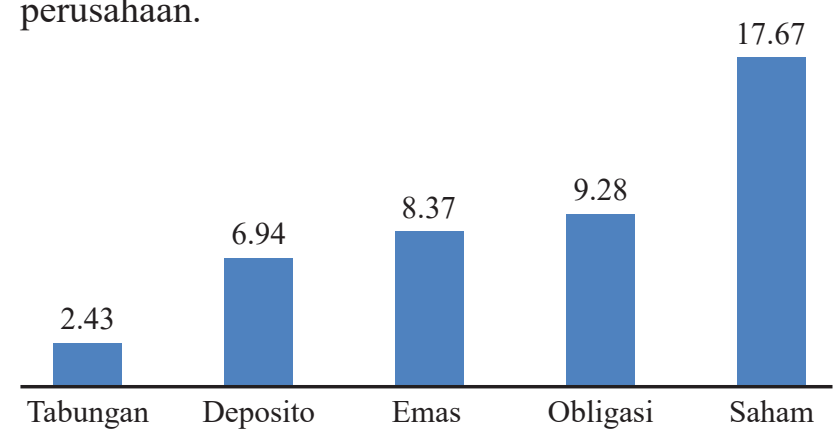

Sumber: Indonesia Stock Exchange, 2017

Gambar 1. Keuntungan Pada Instrumen Keuangan

Setiap tahun pertumbuhan investor di pasar modal Indonesia selalu meningkat, namun jika dibandingkan dengan populasi penduduk masih sangat rendah (Gambar 2). Rendahya minat masyarakat ini disebabkan karena rendahnya pemahaman dan pengetahuan masyarakat mengenai investasi di pasar modal (Merawati \& Putra, 2015). Hal ini juga disampaikan oleh Direktur Utama PT. Bursa Efek Indonesia (BEI) Tito Sulistio (2015) bahwa minat investasi masyarakat yang rendah disebabkan oleh kurangnya pengetahuan dan pengalaman investasi di pasar modal. Diperlukan pengetahuan yang cukup untuk mengetahui berbagai hal mengenai investasi agar masyarakat memiliki kemauan untuk berinvestasi di pasar modal.

Pada Juli 2017 PT. Kustodian Sentral Efek Indonesia (KSEI) mencatat jumlah single investor identification (SID) di Indonesia sebanyak 1.025.414 rekening, jumlah ini terus mengalami peningkatan dibandingkan tahun sebelumnya. Peningkatan ini sebenarnya sangat kecil dibandingkan dengan populasi penduduk di Indonesia sebanyak 257.912.349 jiwa (BPS, Juli 2017), artiya jumlah investor di pasar modal sekitar 0,39\%. Kepala Eksekutif Pengawas Pasar Modal OJK, Nurhaida (2017) menyebutkan bahwa investor pasar modal di negara lain mencapai $20 \%$ hingga 30\%. Survey nasional Otoritas Jasa Keuangan (OJK) pada tahun 2016 menunjukkan bahwa minat masyarakat berinvestasi di pasar modal pada setiap provinsi berbeda-beda namun masih didominasi oleh investor dari daerah Jawa dan Bali.

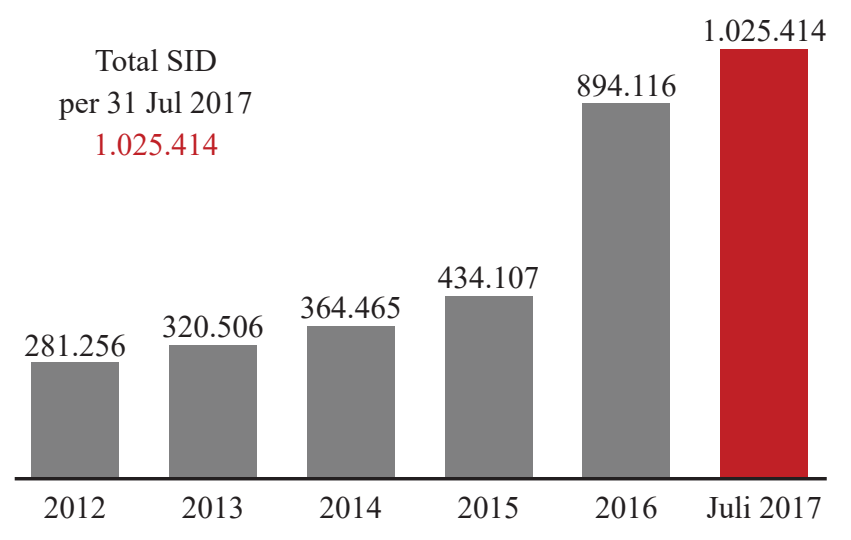

Sumber: KSEI, 2017

Gambar 2. Grafik Pertumbuhan SID

Perkuliahan memperkenalkan berbagai pengetahuan keuangan seperti kinerja keuangan, suku bunga, dampak inflasi, termasuk mengenai investasi dan pasar modal. Widayati (2012) menjelaskan bahwa perkuliahan sangat berperan penting dalam proses pembentukan literasi keuangan mahasiswa. Mahasiswa fakultas ekonomi dan bisnis mengetahui investasi dan pasar modal pada mata kuliah manajemen investasi dan portofolio, teori portofolio dan analisis investasi serta ekonomi moneter. Pembelajaran yang efektif dan efisien akan membantu mahasiswa memiliki kemampuan memahami, menilai, dan bertindak dalam kepentingan keuangan. Luthfi dan Iramani (2008) menyatakan bahwa pembelajaran pada perkuliahan berpengaruh terhadap literasi keuangan.

Penelitian Bhushan \& Medury (2013) mengungkapkan bahwa literasi keuangan adalah kemampuan untuk membuat penilaian informasi dan mengambil keputusan yang efektif tentang penggunaan dan pengeloaan uang. Literasi keuangan sangat penting untuk meningkatkan perekonomian negara Indonesia (Nidar \& Bestari, 2012), melalui pengetahuan yang cukup, pengalaman, serta naluri bisnis untuk menganalisis efek-efek mana yang akan dibeli dalam melakukan investasi di pasar modal (Halim, 2009:36).

Definisi literasi keuangan dikemukakan oleh Remund (2010) meliputi: (1) pengetahuan konsep keuangan, (2) kemampuan mengkomunikasikan konsep keuangan, (3) bakat dalam mengelola keuangan individu, (4) keahlian dalam mengambil keputusan keuangan yang tepat, dan (5) keyakinan dalam perencanaan secara efektif untuk kebutuhan keuangan di masa datang. Literasi keuangan merupakan faktor penting dalam perencanaan dan keputusan keuangan (Austin and Elizabeth, 2014).

Selain pengetahuan, individu memerlukan rasa keyakinan atau kepercayaan diri terhadap kemampuan sehingga dapat mendorong mereka untuk melakukan sesuatu yang dalam ilmu psikologi dikenal sebagai efikasi diri (Farrel, et.al., 2015). Banyak mahasiswa yang telah memiliki pengetahuan keuangan tentang cara berinvestasi di pasar modal dan telah mencoba 
untuk berinvestasi, namun tak sedikit yang mengalami kegagalan. Hal itu terjadi karena tidak mempunyai tujuan keuangan yang spesifik dan belum memiliki keyakinan atau kepercayaan diri untuk mempraktikkan ilmu yang diperoleh mengenai pasar modal yang sesungguhnya.

Literasi keuangan adalah tentang kemampuan memahami uang dan keuangan serta mampu percaya diri menerapkan pengetahuan itu untuk membuat keputusan keuangan yang efektif karena membuat keputusan keuangan yang sehat adalah keterampilan inti yang diperlukan saat ini (Coskuner, 2016). Beberapa faktor yang dapat mempengaruhi litrasi keuangan, diantaranya Indeks Prestasi Kumulatif mahasiswa (Margaretha dan Pambudhi, 2015), pendidikan pengelolaan keuangan keluarga, dan pembelajaran di perguruan tinggi (Widayati, 2012). Literasi keuangan berpengaruh secara signifikan terhadap keputusan keuangan investor (Jariwala, 2015).

Efikasi keuangan memiliki pengaruh pada keputusan yang diambil dalam pengelolaan keuangan para remaja (Danes \& Haberman, 2008). Brandon \& Smith (2009); Bhaskara (2017); Sina (2013) mengemukakan bahwa efikasi keuangan adalah keyakinan positif pada kemampuan untuk berhasil dalam mengelola keuangan. Konsep efikasi keuangan didasari oleh konsep efikasi diri hanya saja berfokus terhadap bidang keuanga. Feist \& Feist (2010:213-215) menyebutkan bahwa efikasi diri seseorang dapat dipengaruhi oleh beberapa fakor, yaitu budaya, jenis kelamin, sifat dari tugas yang dihadapi, dan insentif eksternal. Efikasi diri dipengaruhi secara signifikan oleh pengetahuan keuangan. Mahasiswa dengan pendidikan lebih tinggi akan memiliki efikasi diri lebih tinggi (Heckman and Grable, 2011). Peningkatan efikasi diri merupakan cara yang efektif untuk meningkatkan pemahaman keuangan, karena memungkinkan untuk meminta bantuan keuangan (Lim, et.al., 2014).

Kusmawati (2011) mengungkapkan bahwa minat investasi adalah keinginan untuk mencari tahu tentang jenis suatu investasi, mau meluangkan waktu untuk mempelajari lebih jauh tentang investasi dengan mengikuti pelatihan dan seminar tentang investasi dan mencoba berinvestasi. Pajar (2017) menyatakan bahwa minat investasi merupakan hasrat atau keinginan yang kuat pada seseorang untuk mempelajari segala hal yang berkaitan dengan investasi hingga pada tahap mempraktikannya.

Riyadi (2017) mengemukakan minat investasi mahasiswa secara simultan dipengaruhi oleh manfaat investasi, modal investasi minimal, motivasi, return, dan edukasi, walaupun secara parsial return dan edukasi tidak berpengaruh signifikan. Sedangkan menurut Malik (2017) faktor yang mempengaruhi minat investasi secara positif dan signifikan adalah risiko, pendapatan, dan motivasi. Tandio dan Widanaputra (2016) mengemukakan minat investasi dipengaruhi oleh pelatihan pasar modal dan return, sedangkan persepsi risiko, gender, dan kemajuan teknologi tidak berpengaruh signifikan. Spaseska, et.al. (2016) mengemukakan alasan responden (guru, tenaga administrasi, pekerjasiswa/student-workers, pedagang kecil, dan profesional) tidak berminat investasi di pasar modal adalah lebih tertarik untuk menyimpan di bank, pendapatan rendah, dan risiko tinggi.

Literasi keuangan memiliki pengaruh terbesar dalam menentukan perilaku keputusan individu, dibandingkan dengan faktor sosiodemografi yang meliputi jenis kelamin dan pendapatan (Putri dan Rahyuda, 2017). Hasil penelitian Yulianti dan Silvy (2013) menunjukkan pengetahuan keuangan dan pengalaman keuangan berpengaruh terhadap perilaku perencanaan investasi keuangan keluarga.

Keyakinan atas kemampuan yang dimilikinya dapat mendorong seseorang melakukan sesuatu yang dikenal sebagai efikasi diri. Sina (2013) menyatakan bahwa efikasi keuangan sebagai salah satu pemicu seseorang mengelola keuangan dengan benar dan berusaha memperbaiki cara pengelolaan uangnya sehingga investor yang memiliki tingkat efikasi keuangan yang tinggi akan cenderung lebih tepat dalam mengambil keputusan investasi sesuai kemampuan dan kebutuhannya. Seseorang yang mempunyai keinginan untuk mencoba berinvestasi harus memiliki keyakinan positif agar dapat melakukan dan mengambil keputusan investasi yang tepat guna mendapatkan kesejahteraan di masa datang.

Minat investasi mahasiswa yang rendah dapat diakibatkan oleh pengetahuan yang kurang mengenai investasi di pasar modal, sementara pada era ini pengetahuan mengenai investasi sangatlah penting agar menghindari risiko kerugian yang ditimbulkan akibat ketidaktahuan serta untuk menjaga kondisi keuangan tetap baik di masa datang. Seseorang yang memiliki pengetahuan keuangan disertai rasa percaya akan kemampuan diri dalam mengelola keuangan dapat memahami apa yang akan dihadapinya, seperti mendapatkan keuntungan ataupun menghadapi risiko kerugian. Hipotesis yang diajukan adalah terdapat pengaruh literasi dan efikasi keuangan terhadap minat mahasiswa berinvestasi di pasar modal, secara simultan dan parsial.

\section{METODE}

Metode penelitian yang digunakan adalah deskriptif dan verifikatif. Metode statistik yang digunakan adalah analisis regresi linier berganda, korelasi berganda, dan koefisien determinasi. Populasi adalah mahasiswa aktif yang telah atau sedang menempuh mata kuliah Manajemen Investasi dan Portfolio di program studi Manajemen, Teori Portfolio dan Analisis Investasi di program studi Akuntansi, dan Ekonomi Moneter 1 dan 2 di program studi Ekonomi Pembangunan Fakultas 
Ekonomi dan Bisnis Universitas Pasundan Bandung pada tahun ajaran 2017/2018, sebanyak 489 mahasiswa. Tingkat kesalahan yang ditentukan sebesar 10\% dengan menggunakan metode Slovin maka sampel yang diambil sebanyak 83 mahasiswa. Kuesioner disusun dengan skala semantic differential menggunakan skor 1 sampai dengan 7.

\section{HASIL}

Berdasarkan hasil uji validitas dan reliabilitas, kuesioner literasi dan efikasi keuangan serta minat investasi mahasiswa seluruhnya dinyatakan reliabel dan valid. Berdasarkan hasil analisis deskriptif mengenai literasi keuangan, diperoleh skor rata-rata sebesar 4,86, menunjukkan bahwa tingkat literasi keuangan berada pada kategori baik. Hasil rekapitulasi efikasi keuangan, diperoleh skor rata-rata sebesar 4,77, menunjukkan bahwa tingkat efikasi keuangan berada pada kategori baik. Hasil rekapitulasi minat investasi diperoleh skor rata-rata sebesar 4,90, menunjukan bahwa minat investasi mahasiswa di Fakultas Ekonomi dan Bisnis Universitas Pasundan berada pada kategori baik.

Hasil analisis regresi ditunjukkan pada Tabel 1.

Persamaan regresi berganda untuk literasi keuangan $\left(\mathrm{X}_{1}\right)$ dan efikasi keuangan $\left(\mathrm{X}_{2}\right)$ terhadap minat investasi mahasiswa Fakultas Ekonomi dan Bisnis Universitas Pasundan adalah sebagai berikut:

$$
\mathrm{Y}=3,287+1,008 \mathrm{X}_{1}+0,190 \mathrm{X}_{2}+\varepsilon
$$

Tabel 2. Koefisien Determinasi Simultan

\begin{tabular}{|c|c|c|c|c|}
\hline \multicolumn{5}{|c|}{ Model Summary } \\
\hline Model & $\mathrm{R}$ & $\begin{array}{c}\mathrm{R} \\
\text { Square }\end{array}$ & $\begin{array}{c}\text { Adjusted R } \\
\text { Square }\end{array}$ & $\begin{array}{l}\text { Std. Error of the } \\
\text { Estimate }\end{array}$ \\
\hline 1 &, $924^{\mathrm{a}}$ &, 854 &, 853 & 2,23810 \\
\hline
\end{tabular}

Sumber: Hasil Pengolahan SPSS, 2018

Berdasarkan Tabel 2 diperoleh hasil bahwa nilai korelasi ganda sebesar 0,924 , berarti literasi dan efikasi keuangan memiliki derajat kekuatan hubungan yang sangat kuat terhadap minat investasi mahasiswa. Koefisien determinasi secara simultan sebesar 0,853 , mengindikasikan bahwa secara simultan pengaruh literasi dan efikasi keuangan terhadap minat investasi mahasiswa sebesar $85,3 \%$. Besarnya pengaruh literasi keuangan terhadap minat investasi sebesar $79,9 \%$ dan efikasi keuangan terhadap minat investasi sebesar 5,4\%.

Berdasarkan Tabel 3 diperoleh nilai signifikansi 0,000 yang berarti literasi dan efikasi keuangan secara simultan berpengaruh signifikan terhadap minat investasi mahasiswa Fakultas Ekonomi dan Bisnis Universitas Pasundan.
Tabel 3. Uji Hipotesis Simultan (Uji F)

\begin{tabular}{|c|c|c|c|c|c|c|}
\hline \multicolumn{7}{|c|}{ ANOVA $^{\mathrm{a}}$} \\
\hline & Model & $\begin{array}{l}\text { Sum of } \\
\text { Squares }\end{array}$ & Df & $\begin{array}{l}\text { Mean } \\
\text { Square }\end{array}$ & $\mathrm{F}$ & Sig. \\
\hline \multirow[t]{3}{*}{1} & Regression & 1029,683 & 2 & 5144,841 & 127,101 &, $000^{\mathrm{b}}$ \\
\hline & Residual & 400,727 & 80 & 5,009 & & \\
\hline & Total & 1060,410 & 82 & & & \\
\hline
\end{tabular}

Sumber: Hasil Pengolahan SPSS, 2018

Berdasarkan Tabel 1 diperoleh nilai signifikansi sebesar 0,000, dapat diartikan bahwa literasi keuangan dan efikasi keuangan secara parsial mempunyai pengaruh signifikan terhadap minat investasi mahasiswa di Fakultas Ekonomi dan Bisnis Universitas Pasundan.

\section{PEMBAHASAN}

Skor rata-rata literasi keuangan sebesar 4,86 berada pada kategori baik, artinya mahasiswa Fakultas Ekonomi dan Bisnis Univeristas Pasundan telah memiliki literasi keuangan yang baik namun masih harus ditingkatkan pada beberapa indikator, yaitu (1) pentingnya perencanaan keuangan, (2) memahami instrumen keuangan, (3) mengetahui dan memahami berbagai produk untuk menabung, (4) mengetahui manfaat dan pentingnya asuransi, (5) menetahui waktu pembelian/penjualan investsi, (6) mengetahui kriteria invesatai yang digunakan, (7) mengetahui produk investasi yang akan digunakan, dan (8) mengetahui berbagai return dari investasi.

Efikasi keuangan memperoleh skor rata-rata sebesar 4,77 berada pada kategori baik. Artinya mahasiswa Fakultas Ekonomi dan Bisnis Universitas Pasundan memiliki tingkat keyakinan atau kepercayaan diri yang tinggi, yakin atas kemampuan yang dimilikinya untuk berhasil dalam mengelola kondisi keuangan mereka. Beberapa indikator yang memiliki skor di bawah rata-rata adalah (1) memahami kemampuan diri dalam mengelola dan menghadapi risiko investasi, (2) mengatasi tantangan keuangan, (3) membuat keputusan keuangan, (4) pemilihan aset investasi yang tepat, (5) mengetahui kemampuan dalam berinvestasi walaupin terbatas pengalaman.

Minat investasi mahasiswa di Fakultas Ekonomi dan Bisnis Universitas Pasundan diperoleh skor ratarata 4,90 berada pada kategori baik. Pernyataan yang memiliki skor di bawah rata-rata adalah: (1) mengetahui manfaat investasi, (2) prosedur investasi, (3) keuntungan setiap investasi, (4) kemampuan berinvestasi, (5) berbagai keuntungan investasi.

Berdasarkan hasil pengujian hipotesis menunjukkan literasi dan efikasi keuangan berpengaruh signifikan 
terhadap minat mahasiswa berinvestasi di pasar modal sebesar 85,3\%. Hasil temuan ini mengindikasikan selain literasi keuangan mahasiswa juga harus memiliki efikasi keuangan yang tinggi untuk mendorong diri agar yakin dan mampu berhasil untuk melakukan investasi.

Secara parsial literasi keuangan berpengaruh signifikan terhadap minat mahasiswa berinvestasi di pasar modal sebesar 79,9\%. Literasi keuangan memiliki pengaruh dominan dibandingkan efikasi keuangan. Literasi keuangan meliputi pengetahuan dasar keuangan mengenai simpanan dan pinjaman, asuransi, dan investasi. Mahasiswa yang ingin berinvestasi di pasar modal harus memiliki literasi keuangan yang baik agar dapat memaksimalkan peluang dan meminimalisir risiko. Literasi keuangan mahasiswa didapatkan melalui perkuliahan, seminar, ataupun mencari informasi yang dapat menambah pengetahuan untuk berinvestasi. Hasil penelitian ini sejalan dengan penelitian sebelumnya yang dilakukan oleh Al-Tamimi (2009), Manurung (2009), dan Bhaskara (2017).

Efikasi keuangan berpengaruh positif signifikan terhadap minat mahasiswa berinvestasi di pasar modal sebesar 5,4\%. Efikasi keuangan memiliki pengaruh lebih rendah dibandingkan literasi keuangan karena efikasi keuangan seseorang akan meningkat jika pengetahuan yang dibutuhkan sudah memadai. Hal ini menunjukkan bahwa keyakinan seorang individu didorong oleh pengetahuan yang memadai sehingga mereka akan merasa yakin atas kemampuannya tersebut. Hasil ini mendukung pernyataan Danes \& Haberman (2008); Sina (2014), dan Bhaskara (2017).

\section{KESIMPULAN}

Kesimpulan yang diperoleh: (1) Tingkat literasi keuangan, efikasi keuangan dan minat investasi mahasiswa di Fakultas Ekonomi dan Bisnis Universitas Pasundan berada pada kategori baik atau tinggi, walaupun terdapat beberapa indikator pernyataan yang memiliki skor di bawah rata-rata dan masih harus ditingkatkan, (2) secara simultan literasi dan efikasi keuangan berpengaruh signifikan terhadap minat mahasiswa berinvestasi di pasar modal dengan nilai sebesar 85,3\%. Secara parsial literasi keuangan berpengaruh positif signifikan terhadap minat mahasiswa berinvestasi di pasar modal dengan sebesar 79,9\%, dan efikasi keuangan berpengaruh positif signifikan sebesar 5,4\%.

\section{DAFTAR PUSTAKA}

Adha Riyadi. 2017. Analisis Faktor-Faktor yang Mempengaruhi Minat Mahasiswa Untuk Berinvestasi di Pasar Modal, Jurnal Ekonomi dan Bisnis, Vol. 7 No. 1, 23-41.

Al-Tamimi, H. A. \& Anood Bin Kalli, A. 2009, Financial Literacy and Investment Decision of UAE Investors. The Journal of Risk Finance, Vol. 10 No. 5. 500-516.
Austin, Percy and Elizabeth Arnot-Hill. 2014. Financial Literacy Interventions: Evaluating the Impact and Scope of Financial Literacy Programs on Savings, Retirement and Investment. The Journal of Social, Political and Economic Studies, Vol. 39 No. 3, 290-314.

Badan Pusat Statistik. 2017.

Bhaskara, Widhiyasto Pratomo. 2017. Pengaruh Literasi Keuangan, Efikasi Keuangan, dan Faktor Demografi pada Keputusan Investasi Pasar Keuangan Keluarga di Surabaya. Artikel Ilmiah. eprint.perbanas.ac.id.

Bhushan, P. \& Medury, Y. 2013. Financial Literacy and Its Determinants, International Journal of Engineering, Business and Enterprise Applications (IJEBEA), 4(2), 155-160.

Brandon, D. P. \& Smith, T. R. 2009. Prospective Teachers Financial Knowledge and Teaching SelfEfficacy, Journal of Family and Consumer Sciences Education, Vol. 27 No. 1, 14-28.

Coskuner, Selda. 2016. Understanding Factors Affecting Financial satisfaction. The Influence of Financial Behavior, Financial Knowledge and Demographics. Imperial Journal of Interdiciplinary Research (IJIR), Vol. 2 No. 5, pp 377-385.

Danes, S. M. \& Haberman, H. 2008. Teen Financial Knowledge, Self-Efficacy and Behaviour: A Gendered View, Journal of Financial Counseling and Planning, Vol. 18 No. 2, 48-60.

Farrel, Lisa; Tim R.L. Fry; Leonnora Risse. 2015. The Significance od FinancialSelf-Efficacy in Explaining Women's Personal Finance Behaviour, Journal of Economic Psychology, Vol. 54, 85-99.

Feist, Jess dan Gregory J. Feist. 2010. Teori Kepribadian. Jakarta, Salemba Humanika.

Halim, Abdul. 2009. Analisis Investasi, Salemba Empat, Jakarta.

Heckman, Stuart and Grable, John E. 2011. Testing The Role of Parental Debt Attitudes, Student Income, Depedency Statusand Financial Knowledge Have In Shaping Financial Self-Efficacy Among College Student, College Student Journal, Vol. 45 No. 1, 51-64.

Indonesia Stock Exchange, 2017.

Jariwala, Harsha Vijayakumar. 2015. Analysis of Financial Literacy Level of Retail Individual Investors of Gujarat State and Its Effect on Investment Decision, Journal of Business and Finance Librarianship, Vol. 20 No. 1, 133-168.

Kustodian Sentral Efek Indonesia. 2017.

Kusmawati. 2011. Pengaruh Motivasi Terhadap Minat Berinvestasi di Pasar Modal dengan Pemahaman Investasi dan Usia Sebagai Variabel Moderat, Jurnal Ekonomi dan Informasi Akuntansi (Jenius), Vol. 1 No. 2, 103-117.

Lim, HanNa; Stuart J. Heckman; Jodi C. Letkiewicz, and Catherine P. Montalto. 2014. Financial Stress, SelfEfficacy and Financial Help-Seeking Behavior of 
College Students, Journal of Financial Counseling and Planning, Vol. 25 No. 2, 148-160.

Luthfi \& Iramani. 2008. Financial Literacy Among University Student and Its Implications to The Teaching Method, Jurnal Ekonomi dan Bisnis, Vol. 11 No. 3.

Malik, Ahmad Dahlan. 2017. Analisa Faktor-Faktor yang Mempengaruhi Minat Masyarakat Berinvestasi di Pasar Modal Syariah Melalui Bursa Galeri Investasi UISI, Junral Ekonomi dan Bisnis Islam, Vol. 3 No. 1, 61-84

Manurung, Adler Haymans. 2009. Berinvestasi dan Perlindungan Investor di Pasar Modal. Jurnal, ISSN: 1978-9017, Perbanas Quartely Review, Vol. 2 No. 1, 24-27.

Margaretha, Farah dan Pambudhi, Reza Arief. 2015. Tingkat Literasi Keuangan pad Mahasiswa S-1, Fakultas Ekonomi. Jurnal Manajemen dan Kewirausahaan. Vol. 17 No. 1. Maret. 76 - 85.

Merawati, Luh K. \& I Putu M. J. S. Putra. 2016. Dampak Pelatihan Pasar Modal Terhadap Pengetahuan Investasi dan Minat Berinvestasi. Seminar Nasional oleh Lembaga Penelitian dan Pemberdayaan Masyarakat (LPPM) UNMAS Denpasar, 29-30 Agustus 2016.

Nidar, S. R. \& S. Bestari., 2012.Personal Literacy Among University Students (Case Study at Padjajaran University Students, Bandung, Indonesia), World Journal of Social Sciences, Vol. 2 No. 4, 162-171.

Pajar, Rizky Chaerul. 2017. Pengaruh Motivasi Investasi dan Pengetahuan Investasi Terhadap Minat Investasi di Pasar Modal Pada Mahasiswa FE UNY, Jurnal Keuangan dan Bisnis, Vol. 1 No. 2, 2-11.

Putri, Ni Made Dwiyana Rasuma dan Henny Rahyuda. 2017. Pengaruh Tingkat Financial Literacy dan
Faktor Sosiodemografi Terhadap Keputusan Investasi Individu, E-Jurnal Ekonomi dan Bisnis Universitas Udayana, Vol.6 No. 6, 3407-3434.

Remund, David. L. 2010. Financial Literacy Explicated: The Case For a Clear Definition in an Increasingly Complex Economy, The Journal of Consumer Affairs, Vol. 44 No. 2, 276-295.

Riyadi, Adha. 2017. Analisis Faktor-Faktor yang Mempengaruhi Minat Mahasiswa Untuk Berinvestasi di Pasar Modal, Jurnal Ekonomi dan Bisnis, Vol. 7 No. 1, 23-41.

Spaseska, Tatjana; Aneta Risteska; Gordana Vitanova; Dragica Odzaklieska, and Fanka Risteska. 2016. Analysis of Knowledge About Capital Market Activities in Republic of Macedonia. www. ekonomika.org.rs, Vol. 62 No. 2, 71-83.

Sina, Peter G.. 2013. Financial Efficacy and Financial Satisfaction: Ditinjau dari Perbedaan Gender, Jurnal Manajemen, Vol. 12 No. 2, 173-184.

Sina, Peter G, 2014. Motivasi Sebagai Penentu Perencanaan Keuangan (Suatu Studi Pustaka), Jurnal Ilmiah Akuntansi dan Bisnis, Vol. 9 No. 1, 42-48.

Tandio, Timothius dan A. A. G. P. Widanaputra. 2016. Pengaruh Pelatihan Pasar Modal, Return, Persepsi Risiko, Gender dan Kemajuan Teknologi Pada Minat Investasi Mahasiswa, E-Jurnal Akuntansi Universitas Udayana, Vol. 16 No. 3, 2316-2341.

Widayati, Irin. 2012. Faktor-Faktor yang Mempengaruhi Literasi Finansial Mahasiswa Fakultas Ekonomi dan Bisnis Universitas Brawijaya, Jurnal Akuntansi dan Pendidikan, Vol. 1 No. 1, 89-99.

Yulianti, Norma dan Meliza Silvy. 2013. Sikap Pengelola Keuangan dan Perilaku Perencanaan Investasi Keluarga di Surabaya, Journal of Business and Banking, Vol. 3 No. 1, 57-68.

Tabel 1. Persamaan Regresi

Coefficients $^{\mathrm{a}}$

\begin{tabular}{|c|c|c|c|c|c|c|c|c|c|}
\hline \multirow{2}{*}{\multicolumn{2}{|c|}{ Model }} & \multicolumn{2}{|c|}{$\begin{array}{c}\text { Unstandardized } \\
\text { Coefficients }\end{array}$} & \multirow{2}{*}{$\begin{array}{c}\begin{array}{c}\text { Standardized } \\
\text { Coefficients }\end{array} \\
\text { Beta } \\
\end{array}$} & \multirow[b]{2}{*}{$\mathrm{T}$} & \multirow[b]{2}{*}{ Sig. } & \multicolumn{3}{|c|}{ Correlations } \\
\hline & & $\mathrm{B}$ & Std. Error & & & & Zero-order & Partial & Part \\
\hline \multirow[t]{3}{*}{1} & (Constant) & 3,287 & 1,236 & & 2,659 & ,009 & & & \\
\hline & Literasi Keuangan & 1,008 &, 033 & 1,002 & 30,835 &, 000 & ,798 & ,960 & ,667 \\
\hline & Efikasi Keuangan & ,190 & 044 & ,278 & 4,344 &, 000 & ,195 & ,437 & ,094 \\
\hline
\end{tabular}

a. Dependent Variable: Minat Investasi

Sumber: Hasil Pengolahan SPSS, 2018. 